\title{
Zwei Stellungnahmen zur Botschaft über die technischen Zusammenarbeit und Finanzhilfe zugunsten der Entwicklungsländer
}

\section{CpenEdition}

\section{Journals}

Electronic version

URL: http://journals.openedition.org/sjep/991

DOI: 10.4000/sjep.991

ISSN: 1663-9677

\section{Publisher}

Institut de hautes études internationales et du développement

\section{Printed version}

Date of publication: 1 janvier 1984

Number of pages: 142

ISSN: 1660-5926

\section{Electronic reference}

«Zwei Stellungnahmen zur Botschaft über die technischen Zusammenarbeit und Finanzhilfe zugunsten der Entwicklungsländer », Schweizerisches Jahrbuch für Entwicklungspolitik [Online], 4 | 1984, Online erschienen am: 03 Februar 2013, abgerufen am 08 September 2020. URL : http:// journals.openedition.org/sjep/991 ; DOI : https://doi.org/10.4000/sjep.991 


\section{ZWEI STELLUNGNAHMEN ZUR BOTSCHAFT UEBER DIE TECHNISCHEN ZUSAMMENARBEIT UND FINANZHILFE ZUGUNSTEN DER ENTWICKLUNGSLAENDER}

Die am 19. März 1984 durch den Bundesrat erfolgte Veröffentlichung einer Botschaft an das Parlament, in der die Eröffnung eines Rahmenkredits von 1.800 Mio Franken für eine Laufzeit von drei Jahren zur Fortführung der Zusammenarbeit und der Finanzhilfe zugunsten der Entwicklungsländer vorgeschlagen wird, ist zweifellos eines der markantesten Ereignisse der schweizerischen Politik gegenüber den Ländern der Dritten Welt innerhalb der von diesem Jahrbuch erfassten Berichtszeit.

Diese Botschaft folgt eindeutig der vom Bundesrat seit der Verabschiedung des Bundesgesetzes vom 19. März 1976 über die Entwicklungszusammenarbeit und die internationale humanitäre Hilfe festgesetzten Linie. (In der Ausgabe 1982 des Jahrbuches Schweiz - Dritte Welt hatten wir dieses Gesetzt analysiert : J. Forster, "La coopération de la Suisse au développement : politique et réalisation"; A. Brawand, "La coopération de la Suisse au développement : mesures économiques et commerciales".)

Anlässlich der Veröffentlichung dieser Botschaft schien es uns interessant, zwei in der schweizerischen politischen Debatte über die Entwicklungszusammenarbeit engagierte Persönlichkeiten um ihre Kommentare zu diesem Regierungstext zu bitten. Zu diesem Zweck haben wir uns an Herrn Gilbert Coutau, liberaler Nationalrat Genf, Sekretär für die Westschweiz der Gesellschaft für die Entwicklung der Schweizer Wirtschaft. sowie an Herrn Richard Gerster, Koordinator für Entwicklungspolitik der Arbeitsgemeinschaft Swissaid/Fastenopfer/Brot für Brüder/Helvetas, gewandt. Herr Coutau und Herr Gerster sind beide Mitglieder der beratenden Kommission für internationale Entwicklungszusammenarbeit. 